Article

\title{
Ultrasound-Based Liver Stiffness Surveillance in Patients Treated for Chronic Hepatitis B or C
}

\author{
Sheng-Hung Chen ${ }^{1,2,3}$ (1) and Cheng-Yuan Peng $2,3, *$ (i) \\ 1 Graduate Institute of Clinical Medical Science, School of Medicine, China Medical University, \\ Taichung 40447, Taiwan; d14675@mail.cmuh.org.tw \\ 2 School of Medicine, China Medical University, Taichung 40402, Taiwan \\ 3 Division of Hepatogastroenterology, Department of Internal Medicine, China Medical University Hospital, \\ Taichung 40447, Taiwan \\ * Correspondence: cypeng@mail.cmuh.org.tw; Tel.: +886-4-2205-2121 (ext. 2260); Fax: +886-4-2207-1600
}

Received: 9 March 2018; Accepted: 30 March 2018; Published: 17 April 2018

\begin{abstract}
Evolving modes of ultrasound-based elastography have achieved promising validity and reliability for evaluating liver fibrosis. Liver stiffness (LS) is a valuable biomarker for modeling liver disease progression and regression on a continuous noncategorical scale as changes in LS per year or for determining the LS progression or regression rate for refining LS measurement (LSM)-based prognostics. The paradigm of LSMs has altered the focus from liver fibrosis staging alone to comprehensive liver-relevant risk estimations. However, diverse ranges of cohort characteristics, disease types, surveillance protocols and timeframes, necroinflammatory resolutions or biochemical responses (BRs), factors explaining the magnitude or kinetics in LS change, virologic responses (VRs), fibrosis reversals (FRs), and noninvasive surveillance results have rarely been reviewed collectively. Elastography-based LS surveillance alone conveys chronological and valuable patient information and assists in characterizing worldwide patient cohorts under antiviral treatment by delineating the concurrent time elapsed, VR, BR, and FR. In groups with uniform VRs to direct-acting antivirals for chronic hepatitis $C$ and nucleoside and nucleotide analogs for chronic hepatitis B, decline in LS can be explained using concurrent BR from 24 weeks to 3 years, followed by FR and the time elapsed.
\end{abstract}

Keywords: elastography; liver stiffness; chronic hepatitis B; chronic hepatitis C; liver fibrosis; cirrhosis

\section{Introduction}

Chronic hepatitis $(\mathrm{CH}) \mathrm{B}$ and $\mathrm{C}$ treatment is a major global healthcare challenge. Antiviral treatment can alter natural history and reduce risks of cirrhosis, hepatic decompensation, and hepatocellular carcinoma [1,2]. Antiviral therapy in patients with $\mathrm{CHB}$ with decompensated cirrhosis improves hepatic reserve and reduces mortality [2,3]. With the advent of direct-acting antivirals (DAAs) for CHC, recent studies have demonstrated that DAA therapy can improve hepatic reserve and delay progression in patients with $\mathrm{CHC}$ with decompensated cirrhosis [4]. Furthermore, most patients with $\mathrm{CHB}$ or $\mathrm{CHC}$ - even those without a treatment response-benefit from antiviral treatment, evidenced by a marked early resolution in hepatic necroinflammation $[5,6]$ and a fibrosis reversal over time $[7,8]$.

However, a virologic response to $\mathrm{CHB}$ or $\mathrm{CHC}$ treatment does not ensure zero risk of liver-related adverse endpoints after virologic response [9-11]. Therefore, both on-treatment and off-treatment parameters over time should be investigated to further gain insight into the natural history and treatment-modified disease course of chronic viral hepatitis [10-12].

Elastography noninvasively quantifies tissue elasticity and stiffness. By using external or internal impulses, elastographic techniques determine tissue stiffness by calculating tissue strains or shear 
wave velocities [13]. Currently, in noninvasive liver fibrosis evaluation in either a clinical or research setting [14], baseline liver stiffness is a well-established and promising noninvasive biomarker for assessing pretreatment fibrosis in patients with chronic liver diseases [15] and for predicting liver-related events [16]. The evolving modes of ultrasound-based elastography possess promising and comparable validity and reliability for evaluating fibrosis $[17,18]$, despite the limitations, ranging from poor acoustic windows to the motion effects related to measurement variability [19].

Recent studies have further revealed that liver stiffness measurement is a promising solution to modeling liver disease progression and regression on a continuous noncategorical scale as changes in liver stiffness per year or liver stiffness progression or regression rate to refine liver stiffness measurement-based prognostics [7,20-23]. Regarding the heterogeneous surveillance intervals in reports using liver stiffness measurements, the durations were significantly shorter either during treatment or between the end of treatment (EOT) and follow-up in patients with CHB and CHC than those reported in histological studies with follow-up periods of up to 10 years [24,25]. Studies applying paired liver biopsies (pre- and post-antiviral treatment) have reported rates of cirrhosis reversal of up to $74 \%$ of patients with $\mathrm{CHB}$ and $18-64 \%$ of patients with $\mathrm{CHC}$ with cirrhosis over long-term intervals of up to 5 and 10 years, respectively [9,24-26]. Nonetheless, the paradigms of liver stiffness measurements have shifted focus from the outdated cross-sectional liver fibrosis staging alone to comprehensive liver-relevant risk estimation [27]. However, diverse ranges of cohort characteristics, disease types, surveillance protocols and timeframes, and necroinflammatory resolution or biochemical responses, factors explaining the magnitude or kinetics in liver stiffness change, virologic responses, fibrosis reversals, and noninvasive surveillance results have rarely been reviewed collectively [28].

In this study, we searched and reviewed representative reports on liver stiffness surveillance with no less than two surveillance visits in PubMed, Medline, and Cochrane Library databases for papers published between January 2010 and January 2018. Articles not written in English were excluded.

\section{2. $\mathrm{CHC}$}

Among liver fibrosis surveillance reports of patients with $\mathrm{CHC}$, comparisons were made in terms of the therapy (including the untreated group), kinetics of liver stiffness, time elapsed, virologic response, and biochemical response (Table 1 ).

A study [29] reported the kinetics and correlates of liver stiffness over an elapsed time on 126 patients with CHC who received pegIFN-based therapy. At the EOT, 48 weeks after the EOT, and 96 weeks after the EOT, liver stiffness declined significantly from the baseline in the group with sustained virologic response (SVR; $n=57 ;-16.2 \%,-32.2 \%$, and $-43.5 \%$ change, respectively) compared with the non-SVR group $(n=69 ;-7.2 \%,-2.1 \%$, and $+17.3 \%$ change, respectively; $p=0.0127$, $p<0.0001$, and $p<0.0001$, respectively). After further stratification by biochemical responses, at the EOT, 48 weeks after the EOT, and 96 weeks after the EOT, liver stiffness still declined significantly in patients with a biochemical response $(n=16 ;-17.9 \%,-30.0 \%$, and $-27.1 \%$, respectively) compared with the group without a biochemical response $(n=53 ;-4.1 \%,+6.4 \%$, and $+30.6 \%$, respectively; $p=$ $0.0270, p<0.0001$, and $p<0.0001$, respectively) among patients without SVR. Therefore, both virologic response and biochemical response influenced the decline in liver stiffness.

In another study including 180 patients [30], liver stiffness declined significantly from the baseline in the SVR $(n=93)$ and relapse $(n=28)$ groups, but not in the nonresponder $(n=24)$ or untreated $(n=35)$ group. Correlation among the declines in liver stiffness were further estimated through univariate and multiple regressions in the group with relatively high pretreatment liver stiffness values (deduced as METAVIR F3 or F4 stages, $n=67$ ). This indicated that the beneficial effects of pegIFN-based therapy on the decline in liver stiffness were independently associated with milder fibrosis stage (also indicated by a lower hyaluronic acid level), more severe inflammatory activity (indicated by a higher alanine aminotransferase (ALT) level) at the baseline, virologic response, and a longer pegIFN therapy course. The reason for this result is that liver stiffness typically reflects the degrees of both fibrosis and necroinflammation and that pretreatment fibrosis is inversely correlated with treatment response. 
SVR is approximately equivalent to the cessation of viral replication, necroinflammation, and fibrosis progression [31]. Patients with long-term virus-eradicated status after SVR develop fewer adverse outcomes, such as cirrhosis, decompensation, and hepatocellular carcinoma, than those without SVR do. In general, post-treatment SVR status outweighed baseline hepatitis $C$ virus (HCV) RNA in the studies to correlate with significant declines in liver stiffness. Apart from studies in which the cohorts were not stratified [32-36], non-SVR generally accounted for nonsignificant declines in liver stiffness. However, those who experienced a relapse in the non-SVR group still could exhibit significant declines in liver stiffness $[30,37,38]$. In the untreated groups recruited in various studies $[29,30,37]$, nonsignificant declines in liver stiffness were observed throughout the timeframes. However, SVR does not necessarily terminate the progression of disease course, particularly in patients with advanced cirrhosis at the baseline [4]. In a cohort of patients $(n=226)$ with HCV-related cirrhosis and clinically significant portal hypertension $(\mathrm{CSPH})$ receiving DAA therapy, hepatic vein pressure gradient decreased by $10 \%$ in $62 \%$ of patients but CSPH persisted in $78 \%$ of patients despite achieving SVR. One third of patients with a reduction in liver stiffness measurement to below $13.6 \mathrm{kPa}$ (cutoff for ruling out CSPH at the baseline) after SVR still had CSPH, indicating the suboptimal discriminative capacity of liver stiffness measurement for patients with CSPH after an SVR [22].

In addition to stratification by the SVR status, baseline liver stiffness values outweighed SVRs in the various regression analyses adopting various baseline and chronological host and viral covariates to explain the declines in liver stiffness [37-40] (Table 1). Declines in liver stiffness tended to be greater in patients with higher baseline liver stiffness values, reflecting the effects of biochemical response on liver stiffness over time [29]. Moreover, the heterogeneity of liver stiffness declines in the group without an SVR (i.e., in several studies, those who relapsed still could achieve a significant reduction in liver stiffness) $[30,37,38]$ also contributed to the nonsignificant effect of SVR status on the declines in liver stiffness over time. In a recent study [38], approximately $80 \%$ of patients experienced a decline in paired liver stiffness values from the baseline to the SVR visit in the stratified subgroups. The overall percentages of patients who exhibited any decline in liver stiffness did not differ significantly among the SVR $(80.8 \%, 177 / 219)$, relapse $(77.8 \%, 21 / 27)$, and nonresponse $(80.0 \%, 8 / 10)$ groups. Similarly, in a previous study [41], $250(76.2 \%)$ out of 328 patients who received DAA-based therapy and paired liver stiffness measurements exhibited an improvement in liver stiffness from the baseline to the SVR visit 12 weeks after treatment.

After adjustment for other baseline covariates through regression analyses, several individual non-pooling studies $[30,35,37]$ identified baseline hepatic necroinflammation or a necroinflammatory decline over time from the study entry date as being significantly correlated with a decline in liver stiffness. Biochemical responses were also revealed to be in parallel with the liver stiffness decline over time [38]. However, only one study has analyzed the two-phased liver stiffness declines or the rapid-to-slow rates of liver stiffness kinetics (typically declines) through liver stiffness surveillance at shorter time intervals by including patients with $\mathrm{CHB}$ [7]. Among the noninvasive liver fibrosis evaluation approaches or indices, elastography-based liver stiffness measurements in particular were affected at an early stage by hepatic necroinflammatory activity [32]. The activity typically remained relatively stable over the later phase. After ALT normalization, liver stiffness continued to decline gradually, reflecting the ongoing occurrence of fibrosis reversal over time [7,8]. Therefore, lower cutoff values than those acquired at the treatment baseline have been recommended for surveillance by dichotomizing the fibrosis stages in patients with $\mathrm{CHC}$ using elastography on and off treatments [32,34,42]. Furthermore, a large-scale study is required to validate these proposed cutoff values for the prediction of fibrosis stage in treatment-experienced patients. Moreover, experiences in both clinical and research settings have revealed concordances and discordances between different fibrosis evaluation measures [43]. However, a combination of evaluation measures may enhance diagnostic performance [43,44].

Despite the lack of a critical evaluation of the potential for publication bias and quality and pooling of the original data for overall estimations among the reviewed contributions, the current study provides valuable perspectives regarding liver stiffness surveillance. 
In addition to virologic response and biochemical response, surges in the trajectories of liver stiffness values over time may provide a warning for conditions such as hyperbilirubinemia or excessive necroinflammatory flare-ups, particularly during DAA therapy for $\mathrm{CHC}$, excessive alcohol consumption, exposure to hepatotoxins, viral reactivations, superinfections, or relapses. Among patients that ordinarily experience declining liver stiffness values over time, any marked increase in liver stiffness may prompt medical professionals to implement further differential diagnoses for the examinee, potentially requiring further medical attention at any time point during surveillance. The rates of decline (or progression) in liver stiffness may be compared between the pegIFN- and DAA-based groups. Moreover, liver stiffness surveillance may assist in stratifying the patients with $\mathrm{CHC}$ according to early and late rates of decline (or progression) in liver stiffness to implement estimates through time-dependent approaches [45] or decision-tree algorithms [46] for future liver-related endpoints. 
Table 1. Published studies on liver stiffness surveillance in patients with chronic hepatitis C.

\begin{tabular}{|c|c|c|c|c|c|c|c|}
\hline Study/Year & Size & Therapy (Based) & $\begin{array}{l}\text { Off-Treatment } \\
\text { Timeframes }\end{array}$ & $\begin{array}{l}\text { Groups with Nonsignificant } \\
\text { LS Declines }\end{array}$ & $\begin{array}{l}\text { Groups with Significant }^{a} \\
\text { LS Declines }\end{array}$ & LS-Decline Correlates $^{b}$ & SVR-Status Correlates ${ }^{\mathrm{b}}$ \\
\hline Ogawa 2009 [29] & 145 & PegIFN & EOT-wk48-wk96 & NSVR with no BR/untreated & SVR/NSVR with BR & NA & NA \\
\hline Arima 2010 [30] & 180 & $\begin{array}{c}\text { IFN } \\
\text { PegIFN }\end{array}$ & EOT-wk48-wk96 & Nonresponders/untreated & SVR/relapsers & $\begin{array}{l}\text { Milder fibrosis stages, lower hyaluronic acid levels, longer } \\
\text { pegIFN treatment, SVR, higher ALT levels in the group } \\
\text { with higher baseline LS values (deduced F3, F4) }\end{array}$ & NA \\
\hline Wang 2010 [39] & 144 & $\begin{array}{c}\text { IFN } \\
\text { pegIFN }\end{array}$ & EOT-y5 & NSVR & SVR & $\begin{array}{l}\text { Rapid LS declines: higher baseline LS; slow LS declines: } \\
\text { advanced pretreatment fibrosis stages/higher BMI/longer } \\
\text { time remission }\end{array}$ & NA \\
\hline Hézode 2011 [47] & 91 & PegIFN & EOT-wk24 & NSVR & SVR & SVR & $\mathrm{NA}$ \\
\hline Martinez 2012 [37] & 515 & PegIFN & EOT-wk72 & Non-responders/untreated & SVR/relapsers & $\begin{array}{l}\text { Higher baseline LS/ALT levels/antiviral therapy/non-1 } \\
\text { genotypes }\end{array}$ & NA \\
\hline Stasi 2013 [48] & 49 & PegIFN & EOT-wk144 & NSVR & SVR & SVR & $\mathrm{NA}$ \\
\hline Salmon 2015 [40] & $98^{\mathrm{c}}$ & $\begin{array}{c}\text { PegIFN } \\
\text { DAA }\end{array}$ & EOT-y3 & NSVR & SVR & SVR/higher baseline LS/lower AST & NA \\
\hline Moser 2016 [32] & 53 & DAA & $\begin{array}{l}\text { On-treatment } \\
\text { follow-up alone } \\
\text { (1-6 wk from } \\
\text { baseline) }\end{array}$ & No stratified groups & No stratified groups & NA & NA \\
\hline Bachofner 2017 [33] & 392 & DAA & EOT-wk72 & No stratified groups & No stratified groups & $\mathrm{NA}$ & $\mathrm{NA}$ \\
\hline Chan 2017 [35] & 70 & DAA & EOT-wk48 & No stratified groups & No stratified groups & Higher baseline ALT level/HCV genotype 1 & $\mathrm{NA}$ \\
\hline Elsharkawy 2017 [41] & 337 & DAA & EOT-wk12 & Relapsers & SVR & $\begin{array}{c}\text { Correlated with non improvement in LS: relapsers/lower } \\
\text { baseline LS }\end{array}$ & NA \\
\hline Tada 2017 [36] & 210 & DAA & EOT-wk24 & No stratified groups & No stratified groups & $\mathrm{NA}$ & $\mathrm{NA}$ \\
\hline Tachi 2018 [34] & 176 & $\begin{array}{c}\text { PegIFN } \\
\text { DAA }\end{array}$ & EOT-wk24 & No stratified groups & No stratified groups & $\begin{array}{l}\text { Higher baseline necroinflammatory activity for LS declines } \\
\text { till EOT/significant baseline fibrosis stages for LS declines } \\
\text { till } 24 \mathrm{wk} \text { after EOT }\end{array}$ & NA \\
\hline Łucejko 2018 [49] & 34 & DAA & EOT-wk24-wk96 & No stratified groups & No stratified groups & $\begin{array}{l}\text { Advanced baseline fibrosis stages/higher ALT/lower } \\
\text { HCVcAg }\end{array}$ & NA \\
\hline Chen 2018 [38] & 256 & $\begin{array}{l}\text { PegIFN } \\
\text { DAA }\end{array}$ & EOT-wk24 & Non-responders & SVR/relapsers & Higher baseline LS/lower BMI & $\begin{array}{c}\text { Lower baseline LS/lower } \\
\text { BMI/IL 28B } \\
\text { polymorphisms/RVR }\end{array}$ \\
\hline
\end{tabular}

ALT, alanine aminotransferase; AST, aspartate aminotransferase; BMI, body mass index; BR, biochemical response; DAA, direct-acting antiviral; EOT, end of treatment; HCV, hepatitis C virus; $\mathrm{HCVcAg}$, hepatitis $\mathrm{C}$ virus core antigen; LS, liver stiffness; NA; not available; NSVR, non-sustained virologic response; pegIFN, pegylated interferon; SVR, sustained virologic response; wk, week; $y$, year; LS decline, defined as the value equal to the baseline minus the follow-up; ${ }^{a}$ the time elapsed varied among studies that were fixed or time-dependent; ${ }^{b}$ the correlates with LS-decline and SVR: acquired through multiple regression analysis; ${ }^{\mathrm{c}}$ human immunodeficiency virus/HCV-coinfected. 


\section{3. $\mathrm{CHB}$}

Compared with $\mathrm{CHC}$, the baseline liver stiffness values remained the most crucial of all factors to explain the liver stiffness improvement over follow-up periods (Table 2). Except in the study [50], employing the absolute value of follow-up liver stiffness ( $<7.2 \mathrm{kPa}$ on FibroScan) as the outcome, participants with lower baseline liver stiffness were more likely to achieve favorable outcome than those with higher liver stiffness values.

Table 2. Published studies on liver stiffness surveillance in patients with chronic hepatitis B.

\begin{tabular}{|c|c|c|c|c|c|}
\hline Study/Year & Size & Follow-Up Timeframes & $\begin{array}{l}\text { Baseline } \\
\text { Pathology }\end{array}$ & $\begin{array}{l}\text { Multiple } \\
\text { Biopsies }\end{array}$ & LS-Decline Correlates \\
\hline Ogawa 2011 [52] & 45 & Baseline-yearly-y5/y3-y5 & Yes & No & NA \\
\hline Fung 2011 [51] & 426 & Baseline-y3 & No & No & $\begin{array}{c}\text { Subsequent ALT } \\
\text { normalization in the } \\
\text { treated/persistently normal } \\
\text { ALT in the untreated groups }\end{array}$ \\
\hline Kim 2014 [53] & 83 & $411.5 \pm 149.5$ days & No & No & NA \\
\hline Liang 2017 [7] & 534 & Baseline-wk24-wk102 & Yes & Yes & $\begin{array}{l}{ }^{\text {a }} \text { Higher changes of Ishak } \\
\text { stage }\end{array}$ \\
\hline Li 2017 [54] & 334 & $24 w k$ & No & No & $\begin{array}{c}\text { Higher baseline AST/lower } \\
\text { ALT/higher } \\
\alpha \text {-fetoprotein/higher } \\
\text { LS/longer course of } \\
\text { antiviral therapy }\end{array}$ \\
\hline Chon 2017 [50] & 120 & Baseline-yearly-y5 & Yes & No & $\begin{array}{l}\text { Lower baseline } \mathrm{LS} \text { values } \\
\qquad(<12.0 \mathrm{kPa})\end{array}$ \\
\hline Wu 2017 [8] & 71 & Baseline-wk26-wk53-wk78-wk104 & Yes & Yes & Higher baseline LS \\
\hline Rinaldi 2018 [55] & 189 & Baseline-wk24 & No & No & Higher baseline LS \\
\hline Li 2018 [56] & 104 & Baseline-y3 & Yes & No & NA \\
\hline
\end{tabular}

LS, liver stiffness; wk, week; y, year; LS decline, defined as the value equal to the baseline minus the follow-up; NA, not available; ${ }^{a}$ for the group with paired liver biopsies.

In addition, time elapsed and biochemical response typically superseded the baseline hepatitis B virus DNA, viral genotypes, serology, and several host factors, in their correlation with a decline in liver stiffness [7]. The liver stiffness surveillance of the $\mathrm{CHB}$ cohort was not grouped by virologic response because of the uniform virologic response to antiviral treatment with nucleoside or nucleotide analogs.

Regarding biochemical response, either absolute ALT values or declines in ALT levels rarely showed direct significance after regression analyses. The correlations between necroinflammatory degrees and liver stiffness declines were mostly demonstrated through groups stratified by changes in ALT levels [51] and by the results that changes in ALT levels were parallel with declines in liver stiffness [7].

Few studies have implemented paired liver biopsies to assess the fibrosis reversal. In a study [7], fibrosis reversal was observed in 98 (59.8\%) of 164 patients; these $164(30.7 \%)$ patients were selected from 534 study participants receiving adequate paired liver biopsies at the baseline and week 104 over the course of CHB treatment. Of the 98 patients with fibrosis reversal, $63(64.3 \%), 22(22.4 \%)$, $10(10.2 \%)$, and $3(3.1 \%)$ exhibited 1-, 2-, 3-, and 4-point declines in Ishak fibrosis stages, respectively. After adjustment for changes in ALT and Knodell scores, changes in Ishak fibrosis stage were independently associated with declines in liver stiffness measurement of greater than $30 \%$ from the baseline to week 104 (odds ratio, 1.466; 95\% confidence interval, 1.079-1.992; $p=0.014$ ).

In another study [8], 27 patients received paired liver biopsies. Among the 14 patients with a significant decline in liver stiffness of $\geq 15 \%$ from the baseline to week 78 , up to $12(85.7 \%)$ experienced fibrosis reversal (decline in METAVIR fibrosis $\geq 1$ stage). Among the 13 patients with static liver stiffness values, $10(76.9 \%)$ had stable fibrosis stages on histology, whereas $3(23.1 \%)$ had fibrosis reversal. The Spearman's rank correlation analysis revealed significant correlations between declines in liver stiffness and changes in histological fibrosis stages $(r=0.63, p<0.001)$. 
Therefore, biochemical response, followed by fibrosis reversal and time elapsed, but not the virologic response, aided in understanding of the liver stiffness kinetics in the CHB cohort under surveillance.

In conclusion, liver stiffness could be a promising and significant biomarker in evaluating $\mathrm{CHC}$ or $\mathrm{CHB}$ across on- and off-treatment timeframes [44,57]. Elastography-based liver-stiffness surveillance alone conveys chronological and informative patient information. In addition, it facilitates the characterization of patient cohorts undergoing antiviral treatment worldwide by collaboratively delineating the time elapsed, virologic response, biochemical response, and fibrosis reversal. In groups with uniform virologic responses to DAAs for $\mathrm{CHC}$ and nucleoside and nucleotide analogs for $\mathrm{CHB}$, declines in liver stiffness can be explained by the early concurrent biochemical response over time (from 24 weeks to 3 years), followed by fibrosis reversal and time elapsed. Future studies should quantify the concurrent true liver collagen content and define the fibrosis stage to help specify the kinetics and validate the cutoff values of liver stiffness when dichotomizing fibrosis stages over time.

Acknowledgments: This review was supported in part by a grant (MOST 104-2314-B-039-014) from the Ministry of Science and Technology, Taiwan. This manuscript was edited by Wallace Academic Editing.

Author Contributions: Sheng-Hung Chen and Cheng-Yuan Peng performed the reviews; Sheng-Hung Chen and Cheng-Yuan Peng wrote the paper.

Conflicts of Interest: The authors declare no conflicts of interest.

\section{References}

1. Van der Meer, A.J.; Wedemeyer, H.; Feld, J.J.; Hansen, B.E.; Manns, M.P.; Zeuzem, S.; Janssen, H.L. Is there sufficient evidence to recommend antiviral therapy in hepatitis C? J. Hepatol. 2014, 60, 191-196. [CrossRef] [PubMed]

2. Lok, A.S.; McMahon, B.J.; Brown, R.S., Jr.; Wong, J.B.; Ahmed, A.T.; Farah, W.; Almasri, J.; Alahdab, F.; Benkhadra, K.; Mouchli, M.A.; et al. Antiviral therapy for chronic hepatitis B viral infection in adults: A systematic review and meta-analysis. Hepatology 2016, 63, 284-306. [CrossRef] [PubMed]

3. Peng, C.Y.; Chien, R.N.; Liaw, Y.F. Hepatitis B virus-related decompensated liver cirrhosis: Benefits of antiviral therapy. J. Hepatol. 2012, 57, 442-450. [CrossRef] [PubMed]

4. Curry, M.P. Direct acting antivirals for decompensated cirrhosis. Efficacy and safety are now established. J. Hepatol. 2016, 64, 1206-1207. [CrossRef] [PubMed]

5. Liang, X.E.; Chen, Y.P.; Zhang, Q.; Dai, L.; Zhu, Y.F.; Hou, J.L. Dynamic evaluation of liver stiffness measurement to improve diagnostic accuracy of liver cirrhosis in patients with chronic hepatitis B acute exacerbation. J. Viral Hepat. 2011, 18, 884-891. [CrossRef] [PubMed]

6. Tada, T.; Kumada, T.; Toyoda, H.; Sone, Y.; Takeshima, K.; Ogawa, S.; Goto, T.; Wakahata, A.; Nakashima, M.; Nakamuta, M.; et al. Viral eradication reduces both LS and steatosis in patients with chronic hepatitis C virus infection who received direct-acting anti-viral therapy. Aliment. Pharmacol. Ther. 2018, 47, 1012-1022. [CrossRef] [PubMed]

7. Liang, X.; Xie, Q.; Tan, D.; Ning, Q.; Niu, J.; Bai, X.; Chen, S.; Cheng, J.; Yu, Y.; Wang, H.; et al. Interpretation of liver stiffness measurement-based approach for the monitoring of hepatitis B patients with antiviral therapy: A 2-year prospective study. J. Viral Hepat. 2017, 25, 296-305. [CrossRef] [PubMed]

8. Wu, S.D.; Ding, H.; Liu, L.L.; Zhuang, Y.; Liu, Y.; Cheng, L.S.; Wang, S.Q.; Tseng, Y.J.; Wang, J.Y.; Jiang, W. Longitudinal monitoring of liver stiffness by acoustic radiation force impulse imaging in patients with chronic hepatitis B receiving entecavir. Clin. Res. Hepatol. Gastroenterol. 2017. [CrossRef] [PubMed]

9. Poynard, T.; Moussalli, J.; Munteanu, M.; Thabut, D.; Lebray, P.; Rudler, M.; Ngo, Y.; Thibault, V.; Mkada, H.; Charlotte, F.; Bismut, F.; Deckmyn, O.; et al. Slow regression of liver fibrosis presumed by repeated biomarkers after virological cure in patients with chronic hepatitis C. J. Hepatol. 2013, 59, 675-683. [CrossRef] [PubMed]

10. Lee, M.H.; Huang, C.F.; Lai, H.C.; Lin, C.Y.; Dai, C.Y.; Liu, C.J.; Wang, J.H.; Huang, J.F.; Su, W.P.; Yang, H.C.; et al. Clinical efficacy and post-treatment seromarkers associated with the risk of hepatocellular carcinoma among chronic hepatitis C patients. Sci. Rep. 2017, 7, 3718. [CrossRef] [PubMed] 
11. Chen, C.H.; Lee, C.M.; Lai, H.C.; Hu, T.H.; Su, W.P.; Lu, S.N.; Lin, C.H.; Hung, C.H.; Wang, J.H.; Lee, M.H.; et al. Prediction model of hepatocellular carcinoma risk in Asian patients with chronic hepatitis B treated with entecavir. Oncotarget 2017, 8, 92431-92441. [CrossRef] [PubMed]

12. Yu, M.L.; Huang, C.F.; Yeh, M.L.; Tsai, P.C.; Huang, C.I.; Hsieh, M.H.; Hsieh, M.Y.; Lin, Z.Y.; Chen, S.C.; Huang, J.F.; et al. Time-degenerative factors and the risk of hepatocellular carcinoma after antiviral therapy among hepatitis $C$ virus patients: A model for prioritization of treatment. Clin. Cancer Res. 2017, 23, 1690-1697. [CrossRef] [PubMed]

13. Sigrist, R.M.S.; Liau, J.; Kaffas, A.E.; Chammas, M.C.; Willmann, J.K. Ultrasound elastography: Review of techniques and clinical applications. Theranostics 2017, 7, 1303-1329. [CrossRef] [PubMed]

14. Trivedi, H.D.; Lin, S.C.; Lau, D.T.Y. Noninvasive assessment of fibrosis regression in hepatitis C virus sustained virologic responders. Gastroenterol. Hepatol. 2017, 13, 587-595.

15. Summers, J.A.; Radhakrishnan, M.; Morris, E.; Chalkidou, A.; Rua, T.; Patel, A.; McMillan, V.; Douiri, A.; Wang, Y.; Ayis, S.; Higgins, J.; et al. Virtual Touch ${ }^{\mathrm{TM}}$ Quantification to diagnose and monitor liver fibrosis in hepatitis B and hepatitis C: A NICE medical technology guidance. Appl. Health Econ. Health Policy 2017, 15, 139-154. [CrossRef] [PubMed]

16. Lee, H.W.; Yoo, E.J.; Kim, B.K.; Kim, S.U.; Park, J.Y.; Kim, D.Y.; Ahn, S.H.; Han, K.H. Prediction of development of liver-related events by transient elastography in hepatitis B patients with complete virological response on antiviral therapy. Am. J. Gastroenterol. 2014, 109, 1241-1249. [CrossRef] [PubMed]

17. Ferraioli, G.; Filice, C.; Castera, L.; Choi, B.I.; Sporea, I.; Wilson, S.R.; Cosgrove, D.; Dietrich, C.F.; Amy, D.; Bamber, J.C.; et al. WFUMB guidelines and recommendations for clinical use of ultrasound elastography: Part 3: Liver. Ultrasound Med. Biol. 2015, 41, 1161-1179. [CrossRef] [PubMed]

18. Kennedy, P.; Wagner, M.; Castéra, L.; Hong, C.W.; Johnson, C.L.; Sirlin, C.B.; Taouli, B. Quantitative elastography methods in liver disease: Current evidence and future directions. Radiology 2018, 286, 738-763. [CrossRef] [PubMed]

19. Shin, H.J.; Kim, M.J.; Yoon, C.S.; Lee, K.; Lee, K.S.; Park, J.C.; Lee, M.J.; Yoon, H. Motion effects on the measurement of stiffness on ultrasound shear wave elastography: A moving liver fibrosis phantom study. Med. Ultrasongr. 2018, 1, 14-20. [CrossRef] [PubMed]

20. Christiansen, K.M.; Mössner, B.K.; Hansen, J.F.; Jarnbjer, E.F.; Pedersen, C.; Christensen, P.B. Liver stiffness measurement among patients with chronic hepatitis B and C: Results from a 5-year prospective study. PLoS ONE 2014, 9, e111912. [CrossRef] [PubMed]

21. Erman, A.; Sathya, A.; Nam, A.; Bielecki, J.M.; Feld, J.J.; Thein, H.H.; Wong, W.W.L.; Grootendorst, P.; Krahn, M.D. Estimating chronic hepatitis C prognosis using transient elastography-based liver stiffness: A systematic review and meta-analysis. J. Viral. Hepat. 2017. [CrossRef] [PubMed]

22. Lens, S.; Alvarado-Tapias, E.; Mariño, Z.; Londoño, M.C.; LLop, E.; Martinez, J.; Fortea, J.I.; Ibañez, L.; Ariza, X.; Baiges, A.; et al. Effects of all-oral anti-viral therapy on HVPG and systemic hemodynamics in patients with hepatitis C virus-associated cirrhosis. Gastroenterology 2017, 153, 1273-1283. [CrossRef] [PubMed]

23. Kamarajah, S.K.; Chan, W.K.; Nik Mustapha, N.R.; Mahadeva, S. Repeated liver stiffness measurement compared with paired liver biopsy in patients with non-alcoholic fatty liver disease. Hepatol. Int. 2018, 12, 44-55. [CrossRef] [PubMed]

24. Gonzalez, H.C.; Duarte-Rojo, A. Virologic cure of hepatitis C: Impact on hepatic fibrosis and patient outcomes. Curr. Gastroenterol. Rep. 2016, 18, 32. [CrossRef] [PubMed]

25. Shiratori, Y.; Imazeki, F.; Moriyama, M.; Yano, M.; Arakawa, Y.; Yokosuka, O.; Kuroki, T.; Nishiguchi, S.; Sata, M.; Yamada, G.; et al. Histologic improvement of fibrosis in patients with hepatitis $C$ who have sustained response to interferon therapy. Ann. Intern. Med. 2000, 132, 517-524. [CrossRef] [PubMed]

26. Marcellin, P.; Gane, E.; Buti, M.; Afdhal, N.; Sievert, W.; Jacobson, I.M.; Washington, M.K.; Germanidis, G.; Flaherty, J.F.; Aguilar Schall, R.; et al. Regression of cirrhosis during treatment with tenofovir disoproxil fumarate for chronic hepatitis B: A 5-year open-label follow-up study. Lancet 2013, 381, 468-475. [CrossRef]

27. Tapper, E.B.; Afdhal, N.H. Chapter 8 Noninvasive assessment of disease progression. In Zakim and Boyer's Hepatology, 7th ed.; Boyer, T.D., Sanyal, A.J., Terrault, N.A., Lindor, K.D., Eds.; Elsevier: Amsterdam, The Netherlands, 2017; pp. 117-126, ISBN 9780323446570, 9780323446563. 
28. Singh, S.; Facciorusso, A.; Loomba, R.; Falck-Ytter, Y.T. Magnitude and kinetics of decrease in liver stiffness after anti-viral therapy in patients with chronic hepatitis C: A systematic review and meta-analysis. Clin. Gastroenterol. Hepatol. 2018, 16, 27-38. [CrossRef] [PubMed]

29. Ogawa, E.; Furusyo, N.; Toyoda, K.; Takeoka, H.; Maeda, S.; Hayashi, J. The longitudinal quantitative assessment by transient elastography of chronic hepatitis $C$ patients treated with pegylated interferon alpha-2b and ribavirin. Antivir. Res. 2009, 83, 127-134. [CrossRef] [PubMed]

30. Arima, Y.; Kawabe, N.; Hashimoto, S.; Harata, M.; Nitta, Y.; Murao, M.; Nakano, T.; Shimazaki, H.; Kobayashi, K.; Ichino, N.; et al. Reduction of liver stiffness by interferon treatment in the patients with chronic hepatitis C. Hepatol. Res. 2010, 40, 383-392. [CrossRef] [PubMed]

31. Mauro, E.; Crespo, G.; Montironi, C.; Londoño, M.C.; Díaz, A.; Forns, X.; Navasa, M. Viral eradication and fibrosis resolution in post liver transplant cholestatic hepatitis C. Liver Transpl. 2018. [CrossRef] [PubMed]

32. Moser, S.; Gutic, E.; Schleicher, M.; Gschwantler, M. Early decrease of liver stiffness after initiation of antiviral therapy in patients with chronic hepatitis C. Dig. Liver Dis. 2016, 48, 970-971. [CrossRef] [PubMed]

33. Bachofner, J.A.; Valli, P.V.; Kröger, A.; Bergamin, I.; Künzler, P.; Baserga, A.; Braun, D.; Seifert, B.; Moncsek, A.; Fehr, J.; et al. Direct antiviral agent treatment of chronic hepatitis $\mathrm{C}$ results in rapid regression of transient elastography and fibrosis markers fibrosis- 4 score and aspartate aminotransferase-platelet ratio index. Liver Int. 2017, 37, 369-376. [CrossRef] [PubMed]

34. Tachi, Y.; Hirai, T.; Kojima, Y.; Ishizu, Y.; Honda, T.; Kuzuya, T.; Hayashi, K.; Ishigami, M.; Goto, H. Liver stiffness reduction correlates with histological characteristics of hepatitis $\mathrm{C}$ patients with sustained virological response. Liver Int. 2018, 38, 59-67.

35. Chan, J.; Gogela, N.; Zheng, H.; Lammert, S.; Ajayi, T.; Fricker, Z.; Kim, A.Y.; Robbins, G.K.; Chung, R.T. Direct-acting antiviral therapy for chronic HCV infection results in liver stiffness regression over 12 months post-treatment. Dig. Dis. Sci. 2018, 63, 486-492. [CrossRef] [PubMed]

36. Tada, T.; Kumada, T.; Toyoda, H.; Mizuno, K.; Sone, Y.; Kataoka, S.; Hashinokuchi, S. Improvement of liver stiffness in patients with hepatitis $C$ virus infection who received direct-acting antiviral therapy and achieved sustained virological response. J. Gastroenterol. Hepatol. 2017, 32, 1982-1988. [CrossRef] [PubMed]

37. Martinez, S.M.; Foucher, J.; Combis, J.M.; Métivier, S.; Brunetto, M.; Capron, D.; Bourlière, M.; Bronowicki, J.P.; Dao, T.; Maynard-Muet, M.; et al. Longitudinal liver stiffness assessment in patients with chronic hepatitis C undergoing antiviral therapy. PLoS ONE 2012, 7, e47715. [CrossRef] [PubMed]

38. Chen, S.H.; Lai, H.C.; Chiang, I.P.; Su, W.P.; Lin, C.H.; Kao, J.T.; Chuang, P.H.; Hsu, W.F.; Wang, H.W.; Chen, H.Y.; Huang, G.T.; Peng, C.Y. Changes in liver stiffness measurement using acoustic radiation force impulse elastography after antiviral therapy in patients with chronic hepatitis C. PLoS ONE 2018, 13, e0190455. [CrossRef] [PubMed]

39. Wang, J.H.; Changchien, C.S.; Hung, C.H.; Tung, W.C.; Kee, K.M.; Chen, C.H.; Hu, T.H.; Lee, C.M.; Lu, S.N. Liver stiffness decrease after effective antiviral therapy in patients with chronic hepatitis C: Longitudinal study using FibroScan. J. Gastroenterol. Hepatol. 2010, 25, 964-969. [CrossRef] [PubMed]

40. Salmon, D.; Dabis, F.; Wittkop, L.; Esterle, L.; Sogni, P.; Trimoulet, P.; Izopet, J.; Serfaty, L.; Paradis, V.; Spire, B.; et al. Regression of liver stiffness after sustained hepatitis $\mathrm{C}$ virus (HCV) virological responses among HIV/HCV-coinfected patients. AIDS 2015, 29, 1821-1830.

41. Elsharkawy, A.; Alem, S.A.; Fouad, R.; El Raziky, M.; El Akel, W.; Abdo, M.; Tantawi, O.; AbdAllah, M.; Bourliere, M.; Esmat, G. Changes in liver stiffness measurements and fibrosis scores following sofosbuvir based treatment regimens without interferon. J. Gastroenterol. Hepatol. 2017, 32, 1624-1630. [CrossRef] [PubMed]

42. Tachi, Y.; Hirai, T.; Kojima, Y.; Miyata, A.; Ohara, K.; Ishizu, Y.; Honda, T.; Kuzuya, T.; Hayashi, K.; Ishigami, M.; et al. Liver stiffness measurement using acoustic radiation force impulse elastography in hepatitis C virus-infected patients with a sustained virological response. Aliment. Pharmacol. Ther. 2016, 44, 346-355. [CrossRef] [PubMed]

43. Procopet, B.; Cristea, V.M.; Robic, M.A.; Grigorescu, M.; Agachi, P.S.; Metivier, S.; Peron, J.M.; Selves, J.; Stefanescu, H.; Berzigotti, A.; et al. Serum tests, liver stiffness and artificial neural networks for diagnosing cirrhosis and portal hypertension. Dig. Liver Dis. 2015, 47, 411-416. [CrossRef] [PubMed]

44. Wong, G.L. Non-invasive assessments for liver fibrosis: The crystal ball we long for. J. Gastroenterol. Hepatol. 2018. [CrossRef] [PubMed] 
45. Manousou, P.; Burroughs, A.K.; Tsochatzis, E.; Isgro, G.; Hall, A.; Green, A.; Calvaruso, V.; Ma, G.L.; Gale, J.; Burgess, G.; et al. Digital image analysis of collagen assessment of progression of fibrosis in recurrent $\mathrm{HCV}$ after liver transplantation. J. Hepatol. 2013, 58, 962-968. [CrossRef] [PubMed]

46. Cabassa, P.; Ravanelli, M.; Rossini, A.; Contessi, G.; Almajdalawi, R.; Maroldi, R. Acoustic radiation force impulse quantification of spleen elasticity for assessing liver fibrosis. Abdom. Imaging 2015, 40, 738-744. [CrossRef] [PubMed]

47. Hézode, C.; Castéra, L.; Roudot-Thoraval, F.; Bouvier-Alias, M.; Rosa, I.; Roulot, D.; Leroy, V.; Mallat, A.; Pawlotsky, J.M. Liver stiffness diminishes with antiviral response in chronic hepatitis C. Aliment. Pharmacol. Ther. 2011, 34, 656-663. [CrossRef] [PubMed]

48. Stasi, C.; Arena, U.; Zignego, A.L.; Corti, G.; Monti, M.; Triboli, E.; Pellegrini, E.; Renzo, S.; Leoncini, L.; Marra, F.; et al. Longitudinal assessment of liver stiffness in patients undergoing antiviral treatment for hepatitis C. Dig. Liver Dis. 2013, 45, 840-843. [CrossRef] [PubMed]

49. Łucejko, M.; Flisiak, R. Effect of HCV core antigen and RNA clearance during therapy with direct-acting antivirals on hepatic stiffness measured with shear wave elastography in patients with chronic viral hepatitis C. Appl. Sci. 2018, 8, 198. [CrossRef]

50. Chon, Y.E.; Park, J.Y.; Myoung, S.M.; Jung, K.S.; Kim, B.K.; Kim, S.U.; Kim, D.Y.; Ahn, S.H.; Han, K.H. Improvement of liver fibrosis after long-term antiviral therapy assessed by Fibroscan in chronic hepatitis $\mathrm{B}$ patients with advanced fibrosis. Am. J. Gastroenterol. 2017, 112, 882-891. [CrossRef] [PubMed]

51. Fung, J.; Lai, C.L.; Wong, D.K.; Seto, W.K.; Hung, I.; Yuen, M.F. Significant changes in liver stiffness measurements in patients with chronic hepatitis B: 3-year follow-up study. J. Viral Hepat. 2011, 18, e200-e205. [CrossRef] [PubMed]

52. Ogawa, E.; Furusyo, N.; Murata, M.; Ohnishi, H.; Toyoda, K.; Taniai, H.; Ihara, T.; Ikezaki, H.; Hayashi, T.; Kainuma, M.; et al. Longitudinal assessment of liver stiffness by transient elastography for chronic hepatitis B patients treated with nucleoside analog. Hepatol. Res. 2011, 41, 1178-1188. [CrossRef] [PubMed]

53. Kim, J.K.; Ma, D.W.; Lee, K.S.; Paik, Y.H. Assessment of hepatic fibrosis regression by transient elastography in patients with chronic hepatitis B treated with oral antiviral agents. J. Korean Med. Sci. 2014, 29, 570-575. [CrossRef] [PubMed]

54. Li, X.; Jin, Q.; Zhang, H.; Jing, X.; Ding, Z.; Zhou, H.; Zhang, Z.; Yan, D.; Li, D.; Gao, P.; et al. Changes in liver stiffness and its associated factors during oral antiviral therapy in Chinese patients with chronic hepatitis $B$. Exp. Ther. Med. 2017, 13, 1169-1175. [CrossRef] [PubMed]

55. Rinaldi, L.; Ascione, A.; Messina, V.; Rosato, V.; Valente, G.; Sangiovanni, V.; Zampino, R.; Marrone, A.; Fontanella, L.; de Rosa, N.; et al. Influence of antiviral therapy on the liver stiffness in chronic HBV hepatitis. Infection 2018, 46, 231-238. [CrossRef] [PubMed]

56. Li, Q.; Chen, L.; Zhou, Y. Changes of FibroScan, APRI, and FIB-4 in chronic hepatitis B patients with significant liver histological changes receiving 3-year entecavir therapy. Clin. Exp. Med. 2018. [CrossRef] [PubMed]

57. Qiu, T.; Wang, H.; Song, J.; Guo, G.; Shi, Y.; Luo, Y.; Liu, J. Could ultrasound elastography reflect liver function? Ultrasound Med. Biol. 2018, 44, 779-785. [CrossRef] [PubMed]

(C) 2018 by the authors. Licensee MDPI, Basel, Switzerland. This article is an open access article distributed under the terms and conditions of the Creative Commons Attribution (CC BY) license (http://creativecommons.org/licenses/by/4.0/). 